\title{
Fatigue Assessment of Corroded Deck Longitudinals of Tankers
}

ARTICLE in TRANSACTIONS OF THE ROYAL INSTITUTION OF NAVAL ARCHITECTS PART A: INTERNATIONAL JOURNAL OF MARITIME ENGINEERING · JANUARY 2013

Impact Factor: 0.36

READS

53

4 AUTHORS:

Joško Parunov

University of Zagreb

41 PUBLICATIONS 169 CITATIONS

SEE PROFILE

Yordan Garbatov

University of Lisbon

210 PUBLICATIONS $\quad 1,356$ CITATIONS

SEE PROFILE
Ivana Gledic

University of Zagreb

1 PUBLICATION 0 CITATIONS

SEE PROFILE

Carlos Guedes Soares

University of Lisbon

1,203 PUBLICATIONS 10,171 CITATIONS

SEE PROFILE 


\section{FATIGUE ASSESSMENT OF CORRODED DECK LONGITUDINALS OF TANKERS}

J Parunov, I Gledić, University of Zagreb, Faculty of Mechanical Engineering and Naval Architecture, Croatia. Y Garbatov and C Guedes Soares, Centre for Marine Technology and Engineering (CENTEC), Instituto Superior Técnico, Technical University of Lisbon, Portugal.

\section{SUMMARY}

Fatigue life of deck longitudinals of oil tankers is analysed based on linear elastic fracture mechanics. A parametric formulation for the estimation of stress intensity factors and the Paris-Erdogan law are applied. Long-term effects of corrosion are modelled based on regression equations fitted to thickness measurements made during inspections of two tankers. Parametric studies are performed in order to investigate the importance of the governing parameters of crack propagation. A comparison of the fatigue analyses performed by linear fracture mechanics and S-N approaches is presented.

\section{NOMENCLATURE}

a Crack depth, m

$a_{0} \quad$ Initial crack size, $\mathrm{m}$

$a / 2 c \quad$ Crack aspect ratio

$c \quad$ half of surface crack length, $\mathrm{m}$

C Material parameter (crack growth parameter);

$C^{*} \quad$ Regression constant for corrosion progression

$d$ stress gradient correction factor decay coefficient

$d a / d N \quad$ Crack growth rate

$f_{\Delta \sigma} \quad$ Probability density function of stress range

$F \quad$ Joint geometry function

$F_{E} \quad$ Basic crack shape factor

$F_{G} \quad$ Stress gradient factor

$F_{S} \quad$ Front face factor

$F_{T} \quad$ Back face factor (finite thickness factor)

HGSM Hull girder section modulus, $\mathrm{m}^{3}$

$I \quad$ Regression constant for corrosion progression

$K \quad$ Stress intensity factor, MPa $\mathrm{m}^{0.5}$

$K_{C} \quad$ Fracture toughness, $\mathrm{MPa} \mathrm{m}^{0.5}$

$\triangle K \quad$ Stress intensity factor range, $\mathrm{MPa} \mathrm{m} \mathrm{m}^{0.5}$

$\Delta K_{\text {eff }}$ Effective stress intensity factor range, $\mathrm{MPa} \mathrm{m}^{0.5}$

$K_{g} \quad$ Hot-spot stress concentration factor

$\Delta K_{t h} \quad$ Threshold stress intensity factor range, $\mathrm{MPa} \mathrm{m}^{0.5}$

$K_{w} \quad$ Notch factor

$m \quad$ Material parameter

$n_{0} \quad$ Total number of load cycles

$q \quad$ Stress gradient correction factor decay exponent

$r(t) \quad$ reduction of the midship section modulus

$R \quad$ Stress ratio $\left(R=\sigma_{\min } / \sigma_{\max }\right)$

$S C F \quad$ Total stress concentration factor at notch

SIF Abbreviation for stress intensity factor

$t_{0} \quad$ coating life, years

$U \quad$ Crack closure ratio

\section{Greek symbols \\ $\alpha \quad$ non-dimensioned crack length \\ $\beta \quad$ load interaction coefficient \\ $\lambda \quad$ Material constant \\ $\theta \quad$ Scale parameter of the Weibull distribution \\ $\xi \quad$ Shape parameter of the Weibull distribution \\ $\Delta \sigma \quad$ Nominal stress range, $\mathrm{N} / \mathrm{mm}^{2}$}

$\begin{array}{ll}\Delta \sigma_{e q} & \begin{array}{l}\text { Equivalent constant amplitude stress range, } \\ \mathrm{N} / \mathrm{mm}^{2}\end{array} \\ \Delta \sigma_{0} & \text { Reference stress range, } \mathrm{N} / \mathrm{mm}^{2}\end{array}$

\section{INTRODUCTION}

Fatigue life predictions of ship structural details have traditionally been carried out using S-N approach and the Palmgren-Miner's rule. The principal objective of such approach is to estimate the time to failure in order to ensure a satisfactory design lifetime of ship structural components.

For fatigue life assessments different procedures have been developed based on databases of the fatigue behaviour of welded structural components as a result of both tests and theoretical investigations [1] [2]. A fatigue analysis includes the wave induced loading [3], the stress distribution in the structure [4], the model of fatigue damage (S-N approach) or fracture mechanics approach [5] and the probabilistic evaluation of the different steps to arrive at a safety index or time dependent reliability [6].

The analysis of stresses is a complex task due to the complexity of a ship structure. The most accepted methods are the hot spot stress approach [7] and the effective notch stress approach [8]. Recently, new structural approaches were developed in [9] and [10].

Fracture mechanics has been applied to determine the fatigue life of cracked components [11]. A finite element analysis procedure for the development of a probabilistic crack growth model for a stiffened panel has been proposed in [12], allowing for the existence of multiple cracks both in the stiffeners and in the plate and accounting for the correlation between them. The developed probabilistic model may be used for fatigue crack growth analysis and is suitable for reliability assessment of a stiffened panel subjected to correlated crack growth [13]. Recent developments in fatigue assessment methods are provided by the ISSC, Committee on Fatigue and Fracture [14]. 
Welded structures are not perfect and their behaviour depends on a variety of influential factors, namely geometric and material properties, loadings, initial or post built imperfections, deterioration, crack propagation, denting etc. The imperfections change permanently the structural capacity of welded structures that initially have been designed to resist loadings, keeping a certain level of safety.

Corrosion can also impact the fatigue strength, the geometry of the structural component changes with time and as a result, the nominal stress and the stress levels around the hot spot increase with different intensities (e.g. Garbatov, et al. [15], Moan and Ayala-Uraga [16]).

The present paper aims to analyse the fatigue life of main deck structural components of ageing oil tankers using linear elastic fracture mechanics and a parametric formulation to estimate stress intensity factors. The presence of cracks in the deck structure of oil tankers is an important concern for the marine industry because the crack propagation will reduce the collapse strength of the deck-stiffened panels and consequently decrease the ultimate hull girder capacity of ship structures. Furthermore, the effect of crack growth can be even more critical as a result of imperfections that exist in ship structures as demonstrated in [17]. System reliability approach of ship hull structures under corrosion and fatigue is proposed in [18] and [19]. An evidence of the importance of fatigue for global ship strength is the "fatigue section modulus", newly introduced into Common Structural Rules for Double-hull Oil Tankers, which is a simplified fatigue control measure against the fatigue hull girder stresses in the longitudinal deck structure [20].

In the first section of the paper, two single hull tankers built in the nineteen-eighties are described as well as details of the connection of main deck longitudinals with the stiffener of deck transverse, where a crack is assumed to initiate. In the following sections, a procedure is proposed to estimate the fatigue life of main deck longitudinals based on the Paris-Erdogan law [5]. The intention is to use a procedure that is of comparable simplicity as the conventional S-N approach.

The corrosion, represented as a time dependent function, decreases the plate thickness and affects the midship section modulus, resulting in an increase in stresses. The midship section modulus, as a function of time, is defined by a regression analysis based on corrosion thickness measurements, taken during regular surveys [21]. After that, the case study of crack propagation in deck longitudinals is presented. Parametric studies are performed in order to investigate the importance of the governing parameters of crack propagation. Finally, a comparison of fatigue analyses performed by linear fracture mechanics and S-N approaches is presented.

\section{SHIPS STRUCTURAL DESCRIPTION}

The structural detail considered in the present analysis is located at the intersection between a deck transverse and deck longitudinal. It is assumed that the crack is initiated at the vicinity of the weld toe as a two-dimensional surface crack (see Figure 1 and 2). The structural detail is subjected to fatigue loading because of the vertical wave induced bending moment. Two single-hull tankers built in the early nineteen-eighties with principal particulars shown in Table 1 are studied here. The first ship, Ship I, is a tanker whose deck structure is built of high tensile steel, with the yield stress of $315 \mathrm{MPa}$, with a $\mathrm{T}$ profile of deck longitudinals. The second ship, Ship II, is built of mild steel with the yield stress of $235 \mathrm{MPa}$ with a flat bar profile of deck longitudinals.

In the case of a $\mathrm{T}$ profile longitudinal stiffener, the crack propagation is assessed based on the ratio $a / h$, where $a$ is the crack depth and $h$ the flange thickness. The flange thickness, $h=0.019 \mathrm{~m}$ is assumed to be an indicator for achieving the critical crack depth. When the crack depth reaches the flange thickness, the crack propagates further as a trough-thickness crack. The through-thickness crack propagates rather fast in the case of a $\mathrm{T}$ profile longitudinal stiffener as has been confirmed by the experimental and numerical investigations reported by Jang, et al. [22].

Table 1: Principal particulars of ships

\begin{tabular}{|c|c|c|}
\hline & Ship I & Ship II \\
\hline Length, $L[\mathrm{~m}]$ & 237.00 & 203.00 \\
\hline Breadth, $B[\mathrm{~m}]$ & 42.00 & 48.00 \\
\hline Depth, $D[\mathrm{~m}]$ & 20.50 & 18.00 \\
\hline Block coefficient, $C_{b}[-]$ & 0.80 & 0.77 \\
\hline Midship cross-section area, $A\left[\mathrm{~m}^{2}\right]$ & 4.00 & 4.32 \\
\hline Moment of inertia of the mid-ship section, $I\left[\mathrm{~m}^{4}\right]$ & 269.08 & 260.33 \\
\hline Position of neutral axis, $z_{T}[\mathrm{~m}]$ & 9.44 & 8.88 \\
\hline
\end{tabular}



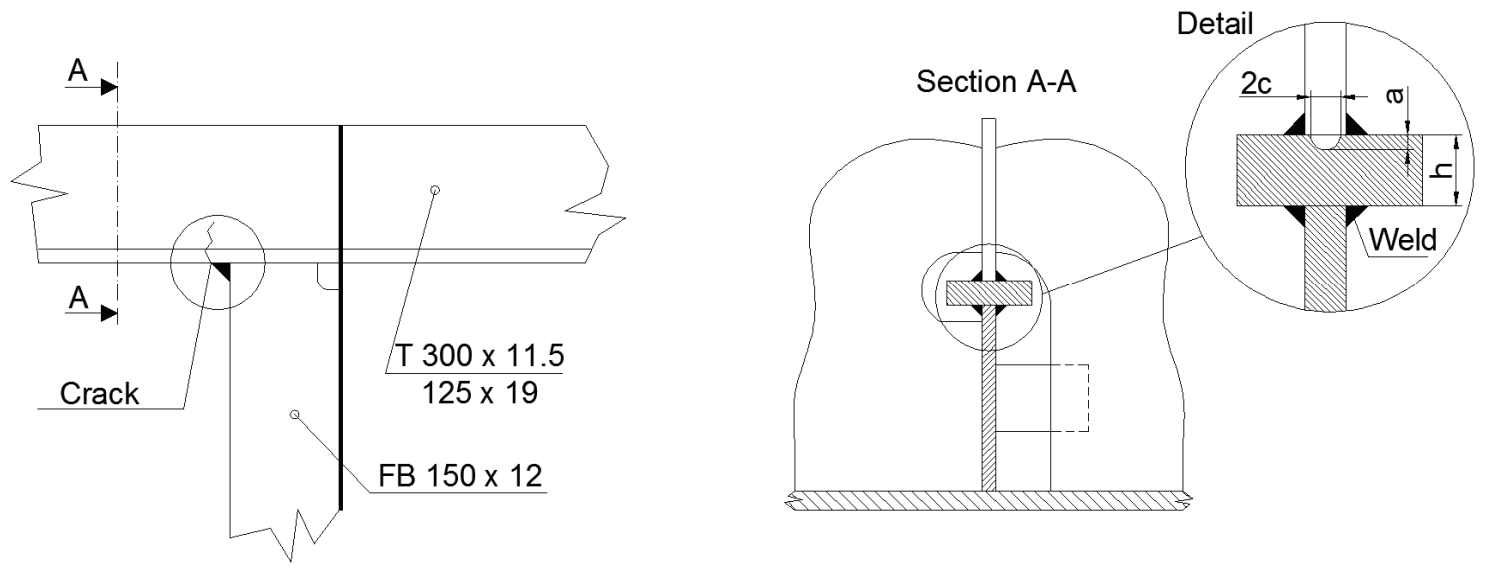

Figure 1: Ship structural detail and crack location, Ship I
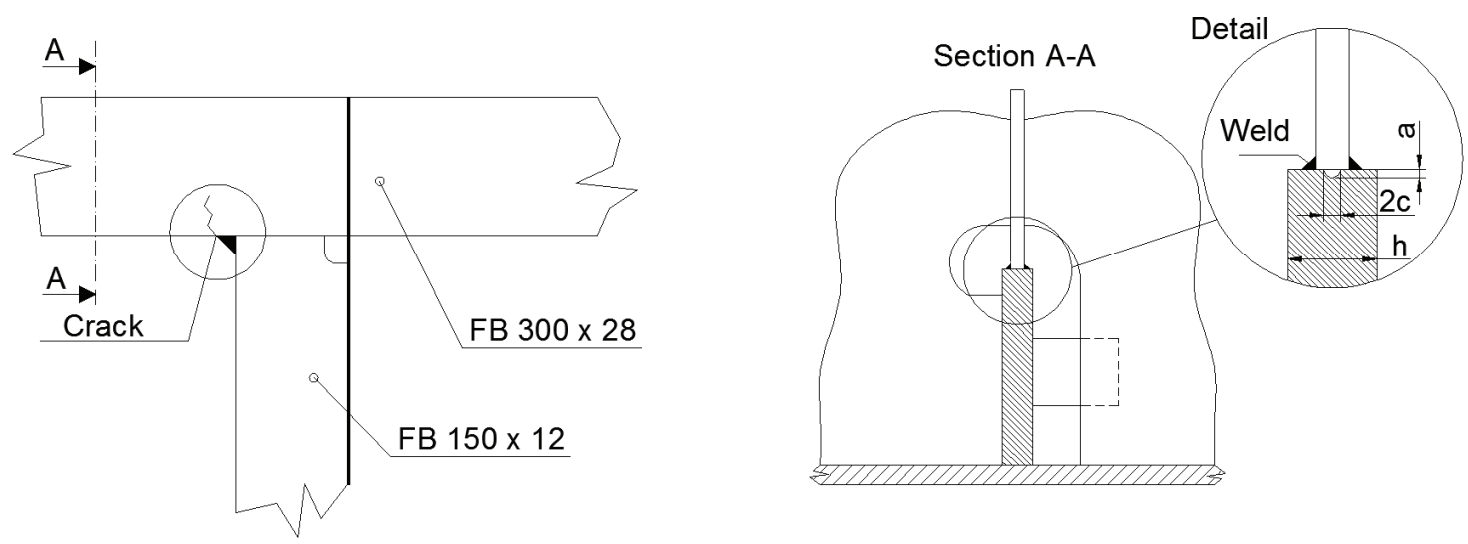

Figure 2: Ship structural detail and crack location, Ship II

In the case of a flat bar longitudinal stiffener, the crack propagation is assessed according to the ratio $2 c / h$ of a crack width of $2 c$ and a thickness of $h$ of the flat bar longitudinal stiffener. The thickness of $h=0.028 \mathrm{~m}$ of the flat bar stiffener is assumed to be an indicator for achieving the critical crack depth.

\section{CRACK GROWTH ASSESSMENT}

The fatigue life may generally be subdivided in a crack initiation period and a crack growth period, ending in failure. The assumption adopted in the present paper is that the crack initiation period in welded joints, that are not stress relieved, occupies a small part of the total life and may be neglected [23]. This assumption is supported by full scale experiments performed by Lotsberg and Salama [24] on details of FPSOs, which are similar to those from Fig. 1 and 2. They concluded that the number of cycles for crack growth is several times (more than 7 times) larger than the number of cycles to initiate $1 \mathrm{~mm}$ crack.

The crack growth rate is defined as a function of the stress intensity factor at the crack tip, assuming that the yielded area around the crack tip is relatively small.
Based on the Paris and Erdogan [5] law, the crack growth rate $d a / d N$ is given as:

$\frac{d a}{d N}=C(\Delta K)^{m}, \Delta K>\Delta K_{t h}$

where the crack growth rate varies from $10^{-3}$ to $10^{-6}$ $\mathrm{mm} /$ cycle for marine structures [23]. $C, m$ are material parameters, $\Delta K$ is the stress intensity factor range at the crack tip and $\Delta K_{t h}$ is the threshold stress intensity factor range.

The Paris-Erdogan equation, as can be seen from Figure 3 [18], remains conservative in region $\mathrm{A}$, and nonconservative in the region $\mathrm{C}$, which leads to a conclusion that most of the fatigue life is consumed when the crack propagates in regions $\mathrm{A}$ and $\mathrm{B}$. When a crack enters region $\mathrm{C}$, i.e. when the stress intensity factor reaches the fracture toughness $K_{c}$, not much fatigue life is left.

The stress range intensity factor range is described by the following equation:

$$
\Delta K=\Delta \sigma F(\mathrm{a}) \sqrt{\pi \cdot \mathrm{a}}
$$


where $\Delta \sigma$ is the nominal stress range, $a$ is the depth of a surface crack and $F(a)$ is the joint geometry function accounting for the crack size, shape, and stress gradient at the crack tip.

If Eq. (2) is inserted in Eq. (1), the Paris-Erdogan law may be presented in the form suitable for numerical integration:

$$
N_{1-2}=\int_{a_{1}}^{a_{2}} \frac{d a}{C(\Delta \sigma \sqrt{\pi a} F(a))^{m}}
$$

where $N_{l-2}$ represents the number of cycles necessary for the crack to propagate from the depth $a_{1}$ to $a_{2}$. Since the joint geometry function $F(a)$ is a function of a crack size and the nominal stress range $\Delta \sigma$ is a nonlinear function of time because of the corrosion degradation, an analytical solution of Eq. (3) is not possible.

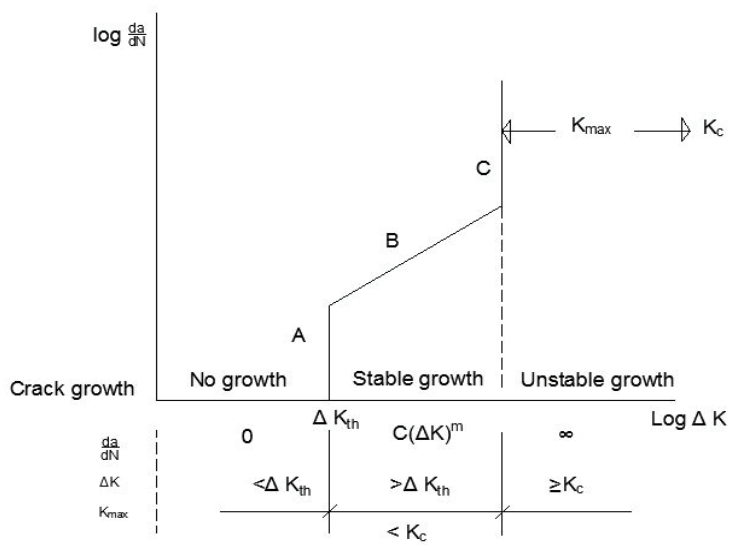

Figure 3: Schematic of crack growth as a function of $\Delta K$

Two alternatives are suggested in BS7910 [21] for numerical integration of the Paris-Erdogan law. The first option is to use simple, a one-stage crack growth relationship, whereas the second alternative proposes a two-stage relationship. Only the former approach, i.e. the simplified but a conservative one-stage fatigue crack growth law is used in the present study.

The material parameters $C$ and $m$ for steels, operating in air or other non-aggressive environments are defined based on BS7910 [25] and, Lassen and Recko [26]. BS7910 recommends $m=3$ and the upper bound of $C$ as $1.64 \cdot 10^{-11}$. Lassen and Recko [26] proposed also 5.79 $10^{-}$ 12 and $9.49 \cdot 10^{-12}$ as the mean value and the mean value plus two standard deviations of $C$, respectively. The material parameter $C$, as defined here, should be used for stresses in $\mathrm{MPa}$ and the crack depth in meters, while for the units in $\mathrm{MPa}$ and $\mathrm{mm}$ the material parameter $C$ should be divided by 31.62 . For steel operating in marine environments, $C=7.27 \cdot 10^{-11}$ is recommended [25].

Based on the results of the experimental tests of mild and high tensile steel, the following expression is suggested in [23]:
$C=\frac{1.315 \cdot 10^{-7}}{28.31^{m}}$

that agrees favourable with the mean value proposed in [26].

The stress intensity factor $K$ is the principal governing parameter for a crack growth in the linear fracture mechanics approach. It incorporates the effects of the stresses and the crack size within the crack tip zone. The stress field at the crack tip may be determined if the stress intensity factor is known. The stress intensity factor depends on load and crack geometry (size and shape) providing a link between a very specific localized tip response and more global structural conditions. In a crack propagation analysis, the stress range intensity factor, $\Delta K$ represents the difference between the maximum and the minimum stress intensity factors.

The joint geometry function is defined as [23]:

$F=F_{E} \cdot F_{S} \cdot F_{T} \cdot F_{G}$

where $F_{E}$ is the basic crack shape factor that accounts for the effect of the crack shape:

$F_{E}=\left\{1+4.5945 \cdot\left(\frac{a}{2 c}\right)^{1.65}\right\}^{-0.5}$

$F_{S}$ is the front face factor that accounts for a free surface at the "mouth" of the crack:

$F_{S}=F_{S}^{\prime}(\sigma(x), \theta) \cdot f_{S}=F_{S}\left(\frac{a}{2 c}\right)=1-0,16 \cdot\left(\frac{a}{2 c}\right)$

where a uniform crack stress distribution $F_{S}{ }^{\prime}=1$ for $\theta=45^{\circ}$ of the weld angle is considered here.

$F_{T}$ is the back face or a finite thickness factor that accounts for the effect of a finite plate thickness:

$F_{T}\left(x=\frac{a}{2 c} ; y=\frac{a}{h}\right)=1+\left(0.008 \cdot y \cdot x^{-2.454}+0.0534 \cdot y^{2} \cdot x^{-1.005}\right)$

The crack aspect ratio $a / 2 c$ is assumed from the equation [23]:

$2 c=6.71+2.58 a$

It should be noted that BS7910 enables a more accurate calculation of the crack aspect ratio as the geometry function is given at various points along the crack front. However, in the present study, the growth is simplified using the one-directional approach by forcing the aspect ratio in accordance to e.g. Eq. (9). Lassen and Recko [26] proposed following expression for the crack shape in a fillet weld joint: 
$2 c=3.83+2.92 a$

Another option for the crack shape that may be considered in the present study is the one experimentally obtained by Jang, et al. [22]:

$2 c=9.81+2.84 a$

The aspect ratio development, according to different studies and loading modes is presented by Moan and Ayala-Uraga [16].

The stress gradient factor $F_{G}$ takes into account the nonuniform crack opening stresses, i.e. the gradient stress field at the crack locus. In the case of a stiffener welded to the flange of the longitudinal stiffener, the stress gradient factor is calculated as:

$$
F_{G}=\frac{S C F}{1+\frac{\alpha^{q}}{d}}
$$

where $\alpha$ represents a non-dimensioned crack length defined as $\alpha=a / h, q$ is the stress gradient correction factor given as $0.6051, d$ is the stress gradient correction factor decay coefficient taken as 1.158 and $S C F$ is the stress concentration factor at the notch, which is defined according to DnV [27] as:

$S C F=K_{g} \cdot K_{w}=2.1$

where $K_{g}$ is the hot spot stress concentration factor due to the gross geometry of the detail considered and $K_{w}$ is the notch stress concentration factor due to the weld geometry.

Variable amplitude fatigue loading, which is inherent to ship structures because of the random wave-induced loads, adds complexity to predicting the crack propagation. The sequence and interaction of loading events may have a major influences on fatigue life. The crack growth depends not only on the number of cycles but also on the exact details of the load history. For example, even a small tensile overload can produce a plastic zone at the tip of the crack, forming compressive residual stresses and crack closure that may retard the growth of the crack. Compressive overloads have a different effect as they can form tensile residual stresses at the crack tip and thus accelerate the growth of cracks. To account for these effects, detailed step-by-step analysis would be required.

Such details of the load history, however, for random wave loading of ship structures are entirely unpredictable. Consequently, there may be limited gains from the detailed analysis and for that reason often simplified models are preferred [28].
One approach to the problem is to define an equivalent constant amplitude stress range, which should cause the same amount of fatigue damage, i.e. a crack growth as the variable amplitude fatigue loading. The equivalent deterministic stress range is defined by adjusting empirically the constant $\beta$ in the following expression:

$\Delta \sigma_{e q}=\left[\int_{0}^{\infty} f_{\Delta \sigma}(\Delta \sigma) \cdot(\Delta \sigma)^{\beta} \cdot \mathrm{d} \Delta \sigma\right]^{1 / \beta}$

where $f_{\Delta \sigma}(\Delta \sigma)$ is the probability density function of the stress range $\Delta \sigma$ and $\beta$ is the interaction coefficient, which can be assumed as $\beta=m=3$ in the case of the Palmgren-Miner's fatigue damage approach.

\section{CASE STUDY}

The risk of failure of ships at sea has risen due to corrosion deterioration of ship hull structures. Numerous statistical data suggest that corrosion is the primary cause of sea accidents, especially for aged ships. Severe corrosion may cause cracks on deck along the ship's service life, which consequently may result in the loss of the entire ship. The hull girder section modulus (HGSM) is the basic measure of ship's longitudinal strength, which is decreasing as a function of time because of corrosion deterioration. Ship Classification Rules assume a constant loss of HGSM during the ship's service life. Although such approach may be practical, but it is not a realistic one since $H G S M$ is a time-dependant non-linear function [21].

The approach adopted here is to consider a corrosion model that provides the trend that is derived from the corrosion mechanism and then it fit to the field data. Corrosion thickness measurements for the two single hull tankers were performed during periodic dry-dockings and regular inspections of ships in service after 10, 15 and 20 years. Based on corrosion thickness measurements, HGSM has been determined accounting for the coating life. The reduction of the midship section modulus, $r(t)$ as a result of a structural deterioration, calculated as a function of $H G S M$, is defined as [21]:

$r(t)=1-\frac{\operatorname{HGSM}(t)}{\operatorname{HGSM}(0)}$

where $\operatorname{HGSM}(0)$ is the hull girder section modulus as built and $\operatorname{HGSM}(t)$ is the hull girder section modulus at any year $t$ during the service life.

Eq. 15, which is directly based on the real corroded plate thickness measurement, is fitted to the following regression equation: 
Table 2: Crack propagation descriptors

\begin{tabular}{|c|c|c|}
\hline Features & T profile (Ship I) & FB profile (Ship II) \\
\hline Initial crack size, $a_{0}[\mathrm{~m}]$ & 0.001 & 0.001 \\
\hline Interaction coefficient, $\beta$ & 3 & 3 \\
\hline Shape Weibull parameter, $\xi$ & 0.94 & 0.98 \\
\hline Stress range corresponding to $10^{-5}$ exceeding probability, $\Delta \sigma_{0}[\mathrm{MPa}]$ & 167.3 & 131.7 \\
\hline Crack growth parameter, $m$ & 3 & 3 \\
\hline Crack growth parameter, $C$ & $5.79 \times 10^{-12}$ & $5.79 \times 10^{-12}$ \\
\hline Number of stress cycles in 1 year $N_{L}$ & $2.8 \times 10^{-6}$ & $2.9 \times 10^{-6}$ \\
\hline
\end{tabular}

$$
r(t)=C^{*} \cdot\left(t-t_{0}\right)^{I}
$$

where $t_{0}$ is the equivalent coating life of the entire structure, $C^{*}$ and $I$ are regression constants, which are defined as 5 years, 0.6 and 0.58 for the Ship I and 6 years, 0.6 and 0.86 for the Ship II respectively. The HGSM reduction as a function of time, as shown in Figure 4, demonstrates that the loss is still well below $10 \%$, which is the permissible reduction of HGSM according to the IMO regulations $[21,29]$.

It must be emphasized that the present analysis is considering only the longitudinal stresses because of wave-induced vertical bending moments, which are the dominating in the main deck structure of oil tankers. The structural components in the ship side and bottom will be subjected to lateral pressure inducing other fatigue cracks, propagating in different directions and having thus a different effect on longitudinal strength is expected.

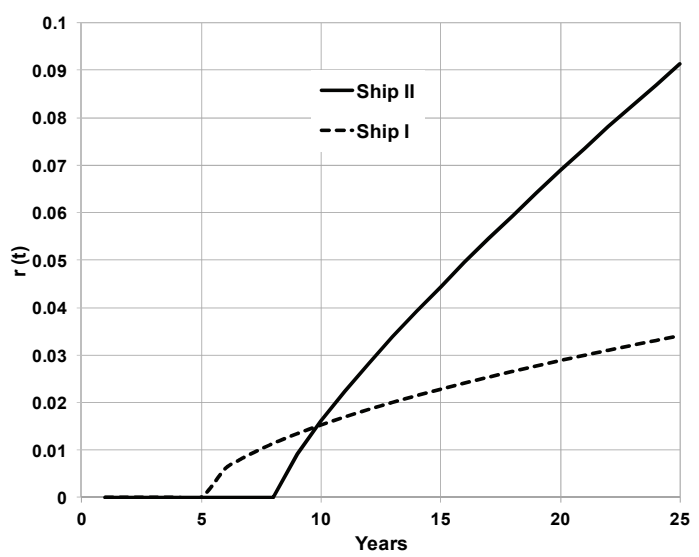

Figure 4: HGSM reduction as a function of time

A crack propagation analysis is performed according to the parameters specified in Table 2 . The initial crack size and the interaction coefficient are assumed according to Almar-Naess [23] and Lassen and Recko [26]. The vertical wave induced bending moments as well as the shape parameter $\xi$ of the Weibull distribution are taken from IACS [20]. Applying Eq. (14), the equivalent stress range is calculated. Furthermore, the stress range is increasing in time because of the HGSM loss. The crack propagations in deck longitudinals are presented in Figure 5. Clearly, the crack propagates more rapidly in Ship I than in Ship II. This may be explained with the fact of using high tensile steel for Ship I, so the waveinduced stresses are higher for Ship I, as has been shown in Table 2. However, details of the geometric function used for the calculation of stress intensity factor, as the finite with correction factor (Eqn. (8)), may also cause this difference in the crack propagation rate. Geometry functions for the two examples are shown in Figure 6, being in remarkable agreement with the geometry function for weld toe crack as presented in [24].

The fatigue life of the deck longitudinal of Ship I is about 16 years, which is lower than the normal design lifetime of ship structural details. This may be due to the fact that mean compressive stresses are not taken into account in the calculation of the crack propagation in Figure 5. The effect of mean compressive stresses may increase the fatigue life considerably, as discussed in Section 5 .

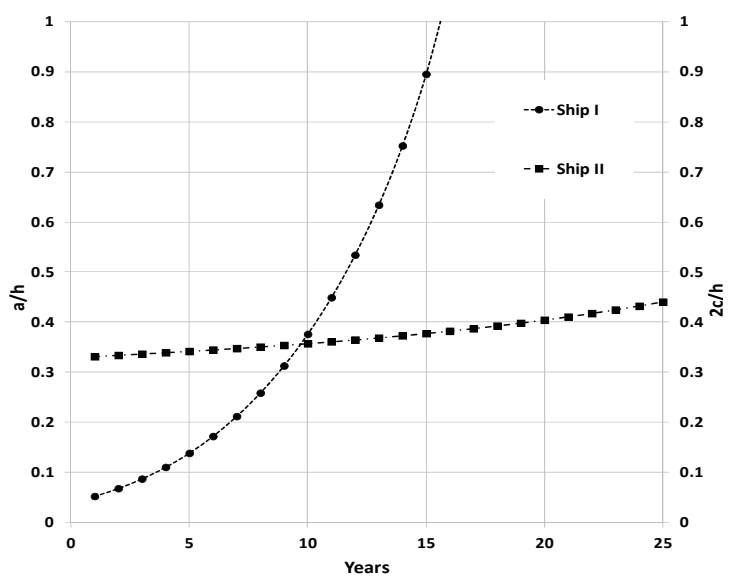

Figure 5: Crack propagation in deck longitudinals

The parametric analysis is carried out to study how the crack propagation is affected by the input data. The parameters considered are the initial crack size $a_{0}$, the crack shape $2 c / a$, the stress ratio $R$, the interaction coefficient $\beta$, the crack growth parameter $C$, the stress concentration factor SCF, the threshold stress intensity 
factor $K_{t h}$, the crack closure parameter $U$ and residual stresses.

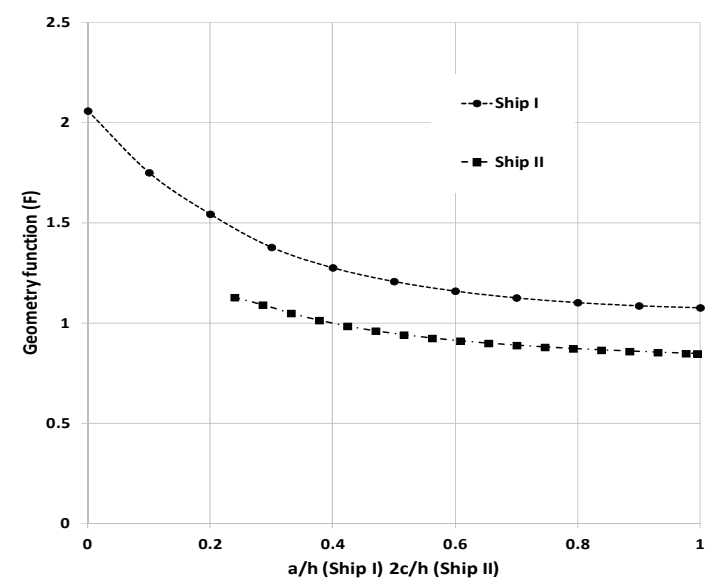

Figure 6: Geometry functions for two ships

In the design phase, the initial crack size is generally unknown. Three different initial crack sizes are assumed in the present study: $0.5 \mathrm{~mm}, 1 \mathrm{~mm}$ and $5 \mathrm{~mm}$. The crack propagation is presented in Figure 7 for Ship I and Ship II respectively. Obviously, the variation of the initial crack size may largely influence the fatigue life. It is to be mentioned that DNV-RP-C203 [30] recommends a crack depth of $0.5 \mathrm{~mm}$ if other documented information about the crack depth is not available.
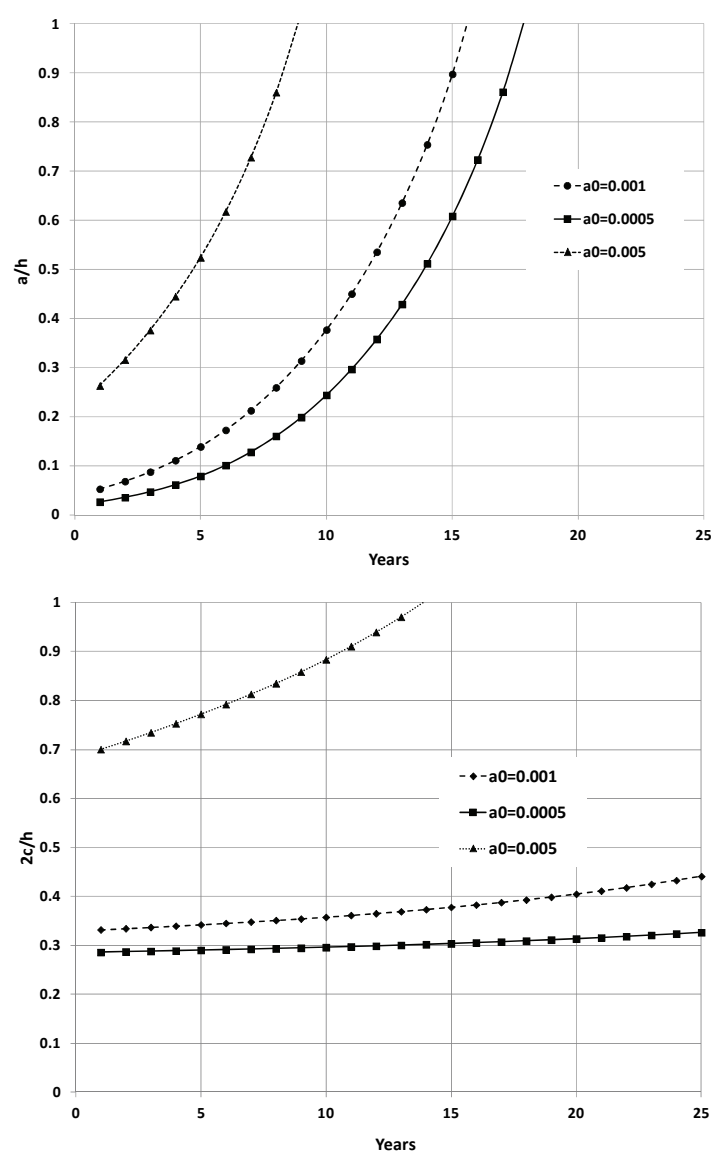

Figure 7: Crack propagation as a function of the initial crack size for Ship I (up) and Ship II (down)
The crack shape influences $\Delta K$ (Eqns. 6-8) significantly and thus the fatigue life. In principle, the aspect ratio should be calculated by a consistent two-dimensional crack growth model [25]. For practical purposes, however, the crack growth is simplified by the one directional approach, using the forcing function of the crack aspect ratio. Most often, a semi-elliptical shape is assumed described by the aspect ratio $2 c / a$. The prediction of the $2 c / a$ evolution during the crack growth is usually empirically done based on the measurements of the fractured surface of welded joints.

In the present study, three different forcing functions for the crack aspect ratio, given by Eqns. 9 to 11, are analysed. The results of the analysis are presented in Figure 8. Here, the different behaviour of the $T$ longitudinal profile and the flat bar longitudinal is evident. For the T-profile longitudinal (Ship I), the assumed crack shape influence both, the crack propagation rate and the final crack size, while for the flat bar (Ship II), the crack propagation rate is not substantially affected.
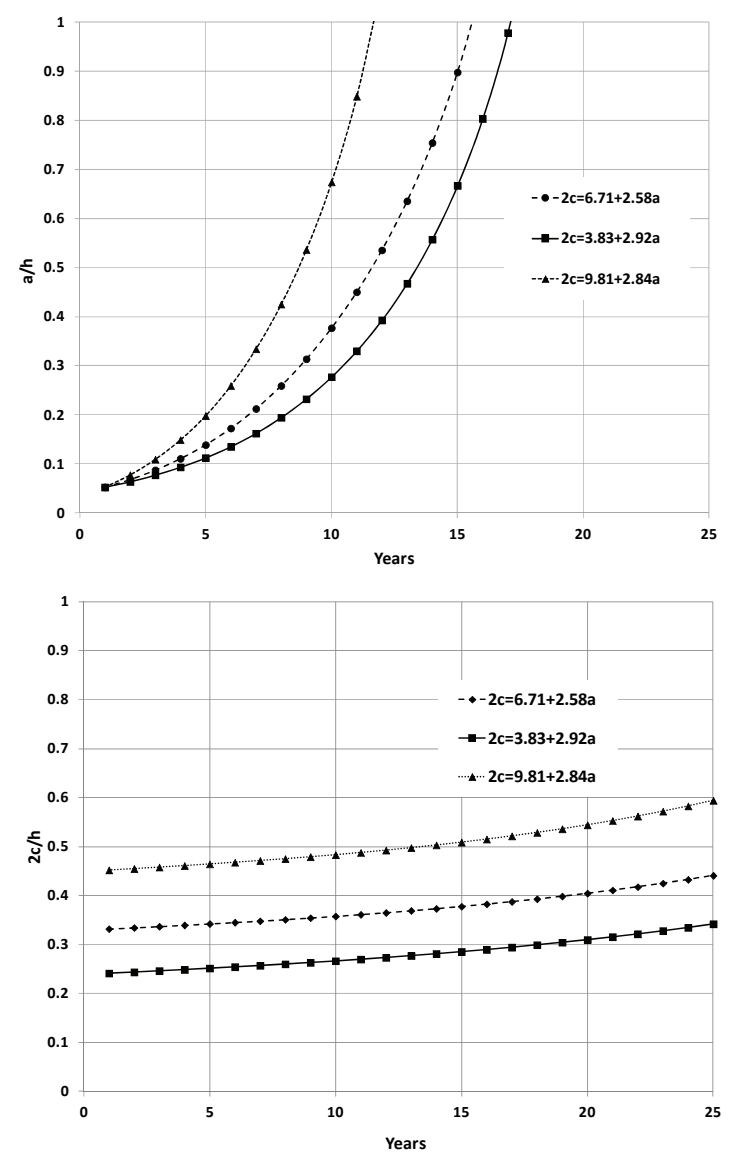

Figure 8: Crack propagation as a function of the assumed forcing function of the crack aspect ratio for Ship I (up) and Ship II (down)

The analysis of the effect of the stress ratio $R=\sigma_{\min } / \sigma_{\max }$ may be performed by the modified Paris-Erdogan law, which also accounts for the fracture toughness, $K_{c}$ [23]: 
$\frac{d a}{d N}=\frac{C \cdot \Delta K^{m}}{(1-R) \cdot K_{c}-\Delta K}$

The fracture toughness $K_{c}$ is the upper bound of stress intensity factor and represents the critical value of the stress intensity factor when the crack propagates in a rapid unstable manner. For an accurate definition of $K_{c}$, knowledge of the precise metallurgic and chemical characteristics of the material is required [22]. Eqn. (17) is also known as the Forman equation [22] and its drawback is that the growth parameters $C$ and $m$ are different from the ones governing the original ParisErdogan law, Eqn. (2). Another commonly used expression to account for the stress ratio $R \geq 0$ is the Walker relationship [28].

$\frac{d a}{d N}=\frac{C \cdot \Delta K^{m}}{(1-R)^{m(1-\lambda)}}$

where $C$ and $m$ are the Paris coefficient and the slope for $R=0$, respectively, and $\lambda$ is a material constant with a typical value around 0.5 [28]. The influence of the variation of the stress ratio $R$ on the crack propagation is presented in Figure 9, using Walker Eqn. (18). The rate of the crack propagation clearly increases with increasing the stress ratio.

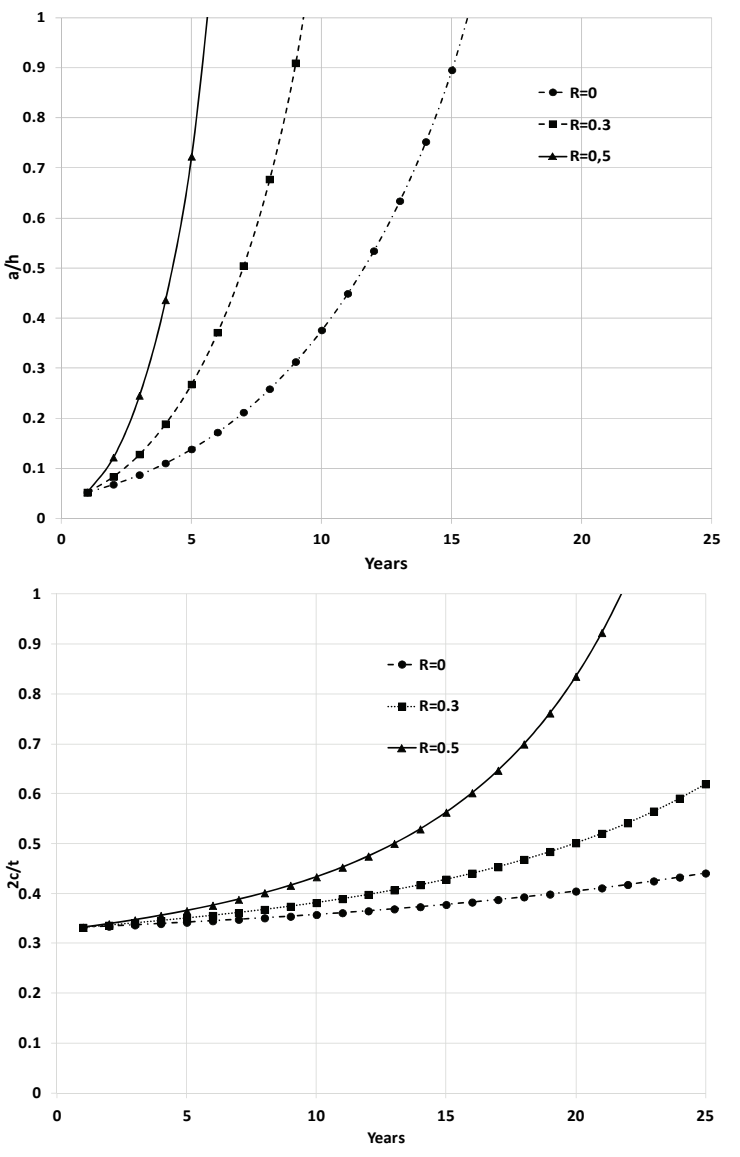

Figure 9: Crack propagation as a function of the ratio $\mathrm{R}$ for Ship I (up) and Ship II (down)
The variable amplitude of loading adds complexity to the problem of predicting fatigue life. The variable stress history is transformed into an equivalent constant stress range that causes the same fatigue damage, i.e. the same crack growth. If the stress range is fitted to the Weibull distribution, then the equivalent constant amplitude stress range may be approximately expressed as [23]:

$\Delta \sigma_{e q} \cong \theta \cdot\left(0.0076 \cdot e^{\{1.6 \cdot x\}+1.26}\right)^{\frac{1}{\beta}}$

where $x=1+\frac{\beta}{\xi}, \xi$ is the shape parameter and $\theta$ is the scale parameter of the Weibull distribution. The interaction coefficient $\beta$ takes into account the effects of the interaction between stress cycles. When the interaction coefficient is $\beta=3$, which in the present case equals the exponent $m$, the interaction between the stress cycles is not taken into consideration, i.e. it corresponds to Palmgren-Miner approach. When $\beta=2$, it corresponds to the equivalent stress range calculated by the rootmean-square rule (RMS). The scale parameter $\theta$ is defined as:

$\theta=\frac{\Delta \sigma_{0}}{\left(\ln n_{0}\right)^{1 / \xi}}$

where $\Delta \sigma_{o}$ is the reference stress range, which is defined as the one exceeded once out of $n_{o}$ cycles and $n_{o}$ is the total number of cycles associated with the fatigue service life

The effect of these two interaction coefficients to the crack propagation is compared in Figure 10 up and down for Ship I and II, respectively. Obviously, $\beta=2$ leads to a considerably slower crack propagation for both ships. Whereas RMS has a defined physical meaning related to energy in many applications, it has no physical significance in fatigue. Hence, it is not likely that such approach would be a rational choice for calculating the equivalent stress range. It would be more appropriate in many cases, $\beta=3$ as such the equivalent stress results in the same damage in S-N approach as corresponding irregular load history. As has been discussed in [23], however, for many offshore structures the interaction effects are so important that failure may occur for the Palmgren-Miner approach [31] much less than unity. With that respect, even using $\beta=3$ should be taken with caution.

Although the described approach for calculating equivalent stress range has no sound theoretical basis, it is a practical empirical approach and hence recommended by some authors like Hughes and Paik [23].

The crack growth parameter $C$ considered in this study is specified in $[25,26]$. The mean value, mean value +2 SD and the upper bound of $C$, applicable for steels 
operating in the air are compared and the results are presented in Figure 11. As may be seen in Figure 11, the variation of the parameter $C$ has a significant influence on the crack propagation rate. Expectedly, when $C$ equals to the upper bound defined by BS7910 [25], the crack propagation is the fastest. It also appears from the results that for Ship II, that the choice of parameter $C$ could have a decisive impact on the conclusions of the crack propagation assessment.

For the structural detail considered here, the $S C F$ is 2.1 according to DnV [27]. The SCF may be reduced either by completely removing the web stiffener or by providing a stiffener with a soft bracket. It should be pointed out that the former solution is employed occasionally in the deck area of oil tankers, while the latter solution is usually used for the side shell longitudinals. The comparison of the crack propagation for the two different SCFs is presented in Figure 12 for Ship I and II, respectively. The lower SCF in Figure 12 corresponds to the case of the flat bar stiffener with a soft bracket.
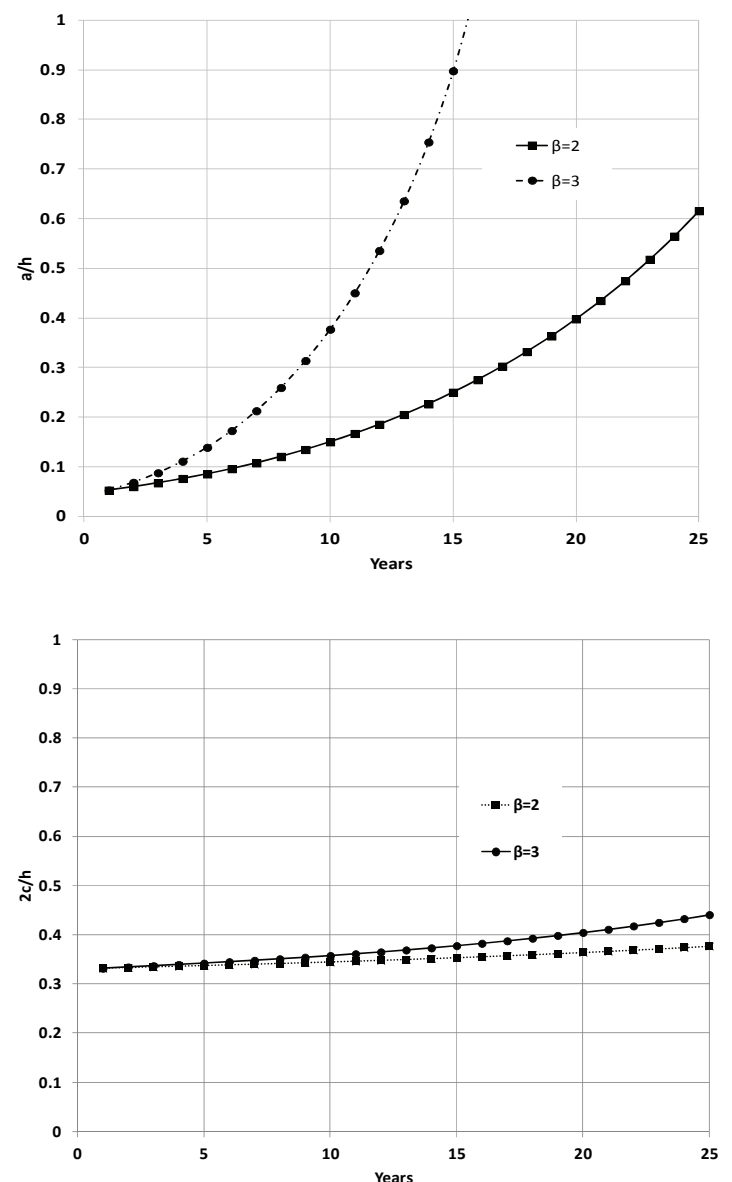

Figure 10: Crack propagation as a function of interaction coefficient $\beta$ for Ship I (up) and Ship II (down)

The effect of the threshold stress intensity factor, $\Delta K_{t h}$ is also analysed. The assumed threshold value reads $\Delta K_{t h}=2 \mathrm{MPa} \mathrm{m}^{0.5}$ [32]. The stress range intensity factor is above 2.6 for Ship I while the whole range of the stress intensity factors is between 1.16 and 1.75 for Ship II. Consequently, the threshold stress intensity factor does not influence the crack propagation of Ship I, while the crack propagation in Ship II would not start at all if the threshold was taken into account.
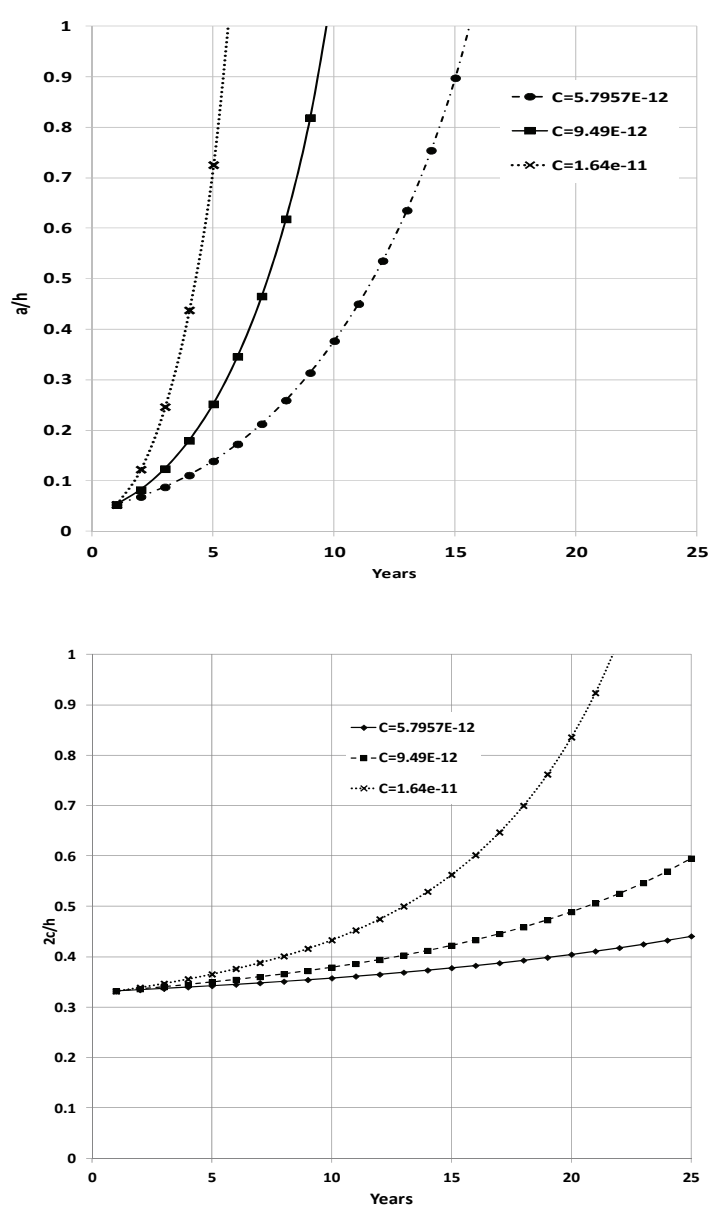

Figure 11: Crack propagation as a function of crack growth parameter $C$ for Ship I (up) and Ship II (down)

One of the factors that affects the crack growth rate is the crack closure effect. Accounting for this effect, fatigue cracks remain closed during a part of the loading cycle under constant and variable amplitude loading. The effective stress intensity factor range, including the crack closure effect, is defined in Eqn. 21 using the crack closure ratio $U$ :

$\Delta K_{\text {eff }}=K_{\max }-K_{o p}=U \cdot \Delta K ; \quad U=\frac{1-\frac{K_{o p}}{K_{\max }}}{1-R}$

where $K_{o p}$ is the SIF at which the crack opens (or closes). According to Lassen and Recko [26], for welded steel joints it may be assumed that for full alternating loading $(R=-1), K_{o p} / K_{\max }=0.2$ implying $U=0.4$, while for $R=0$, $K_{o p} / K_{\max }=0.25$ and $U=0.75$. The crack closure effect to the crack propagation is shown in Figure 13 for Ship I and II, respectively. It appears that the crack closure effect may slow down the crack propagation considerably. 

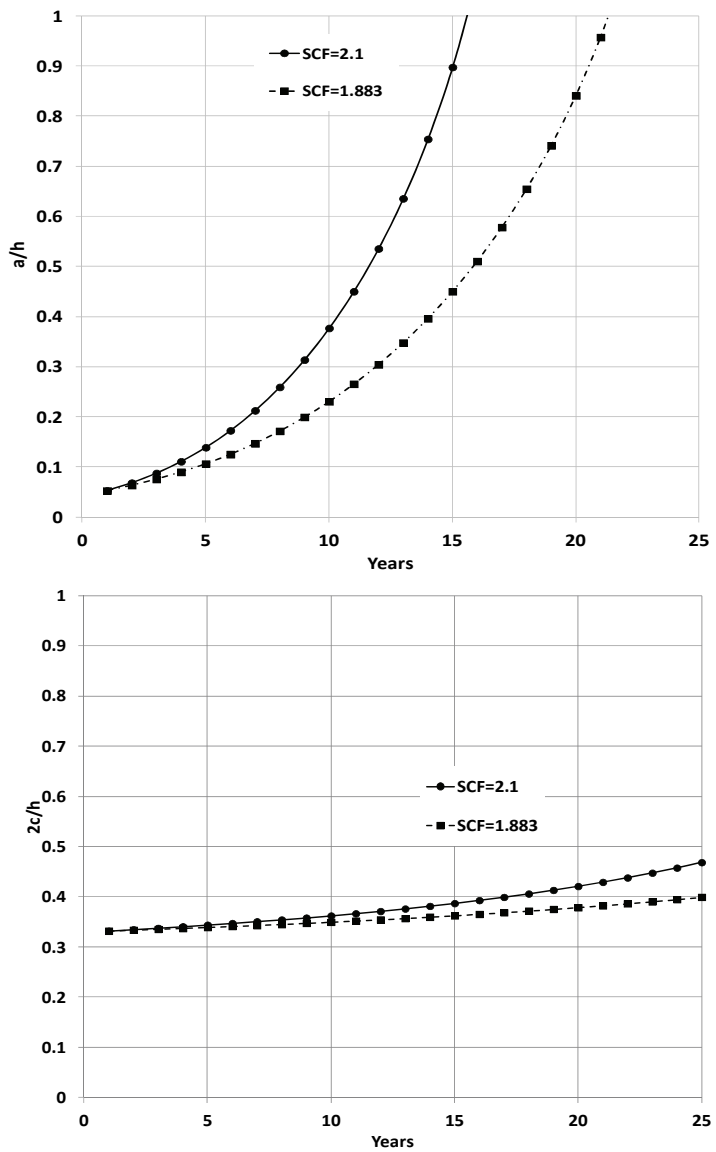

Figure 12: Crack propagation as a function of $S C F$ for Ship I (up) and Ship II (down)

However, it should be emphasised that there is a large uncertainty regarding the validity of the mentioned crack closure ratios and for that reason, the crack closure is seldom used in practical calculations. Although the crack closure effect is very important for the shallow cracks, it is often neglected because the closure effect in a surface crack is generally less significant than the one observed in through-thickness crack geometries [22].

The presence of residual stresses is another important source of uncertainty of the fatigue crack growth near welded areas. For a crack starting from the weld toe end, the stress ratio depends on the residual stress distribution near the toe end. The stress ratio can be adjusted as:

$$
R_{T}=\frac{K_{\min }+K_{r e s}}{K_{\max }+K_{r e s}}
$$

In the case of tensile residual stresses, $R_{T}>R$ and thus the residual stresses have a detrimental effect on the crack propagation. Compressive residual stresses may cause a cracking closure and thus Eq. (21) should be considered. The residual stress intensity factor depends on the residual stress distribution and on the geometry of the welded joints. The quantitative assessment of residual stresses at the web stiffener weld toe end has not yet been reported [22].
For details, similar as those studied in the present paper, Lotsberg and Salama [24] measured tensile residual stresses. However, they also explained that shake-down of residual stresses is expected in the first year of ship service as a consequence of maximum loading. Shakedown effect changes residual stresses from tensile to compressive causing crack closure and reduced fatigue damage. To allow for the influence of residual stresses, a simple and conservative low for $\mathrm{R}>0.5$ is proposed by BS7910 [25].
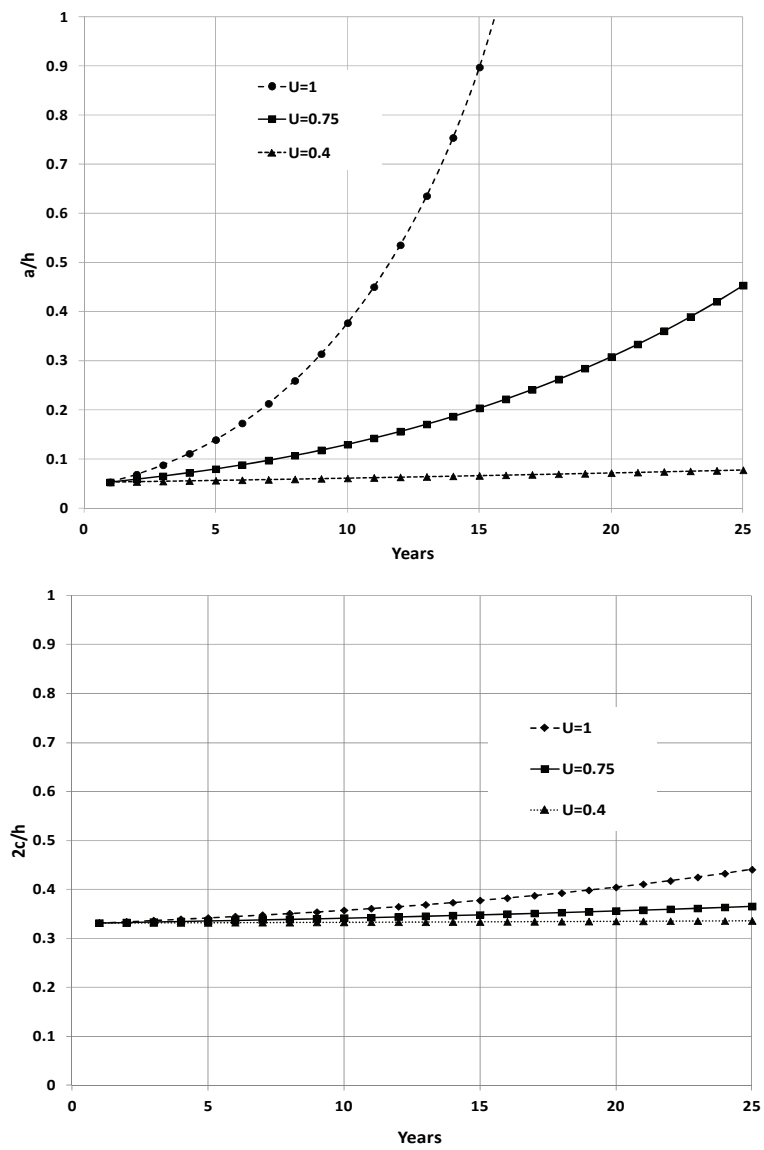

Figure 13: Crack propagation as a function of the crack closure ratio $U$ for Ship I (up) and Ship II (down)

\section{COMPARATIVE ANALYSIS}

The S-N approach often covers the total fatigue life from the crack initiation to final failure. Coupled with a ParisErdogan law [5] to determine the fatigue life consumed during the crack propagation, the S-N approach then enables an approximate estimate of the fatigue life corresponding to the fatigue crack initiation [14]. However, as discussed in Section 3, the crack initiation period is neglected. Therefore, the fatigue life calculated by the $\mathrm{S}-\mathrm{N}$ approach is directly comparable to the one calculated by the crack propagation law.

The S-N approach used in the present study has been defined based on IACS [20] for the F-class of S-N curve. The only difference, comparing to CSR, is that in the present study, the stresses increase due to the corrosion 
wastage of the hull girder section modulus is determined for each year during ship service life. Thus, the stress range increases as the section modulus is reduced because of the corrosion wastage. The accumulated damage, according to the Palmgren-Miner's rule is calculated for each year of the ship's lifetime and is added to the accumulated damage from previous years as has been described by Frost, et al. [33].

The parameters used in the crack propagation assessment are those indicated in Table 4, except that the crack growth parameter $C$ is taken as $9.49 \cdot 10^{-12}$, as recommended by Lassen and Recko [26] for mean plus two standard deviations. This is consistent with the fact that in the S-N approach, the design S-N curves specified in CSR are used, rather than the mean S-N curves [20].

The comparison between the $\mathrm{S}-\mathrm{N}$ and the crack propagation approaches is shown in Figure 14 up and down for Ship I and II, respectively. In the case of Ship I (see Figure 14, up), the accumulated damage closely follows the crack propagation. For both approaches, the predicted fatigue failure occurs much before than the end of the ship's service life. It should be pointed out that such short calculated fatigue life may be explained by the effect of the mean compressive stresses that are not taken into account. Actually, fully loaded oil tankers are in the sagging condition in still water, leading to mean compressive stresses in the main deck structure [34]. Consequently, the fatigue life will increase considerably, as the compressive stresses have a favourable influence reducing to the effective range of stresses [20]. A comparison of $\mathrm{S}-\mathrm{N}$ and crack propagation approaches, taking into account the correction for the mean stresses is presented in Figure 15. Mean compressive stresses allow a reduction of the effective stress range by about $40 \%$ [20].

The mean stress effect has to be accounted for in the fatigue damage assessment as has been recommended in DnV CN 30.7 [27] and DnV-RP-C203 [30] and for tankers as has been postulated in IACS [20]. However, in the first two documents, beneficial influence of the mean compressive stresses is considered only for base material, which is not significantly affected by residual stresses due to welding. Lotsberg and Salama [24] presented evidences from in-service experience and full scale measurements on FPSOs that the fatigue capacity of the hot spots exposed to mean compressive stress are well above those for tensile load cycling.

With Ship II (see Figure 14, down), the crack propagation rate is lower than the rate of damage accumulation and the agreement of the two approaches is less favourable compared to Ship I. A fatigue life bigger than 25 years indicates that the crack does not propagate sufficiently to reduce the load-carrying capacity of the deck longitudinal.

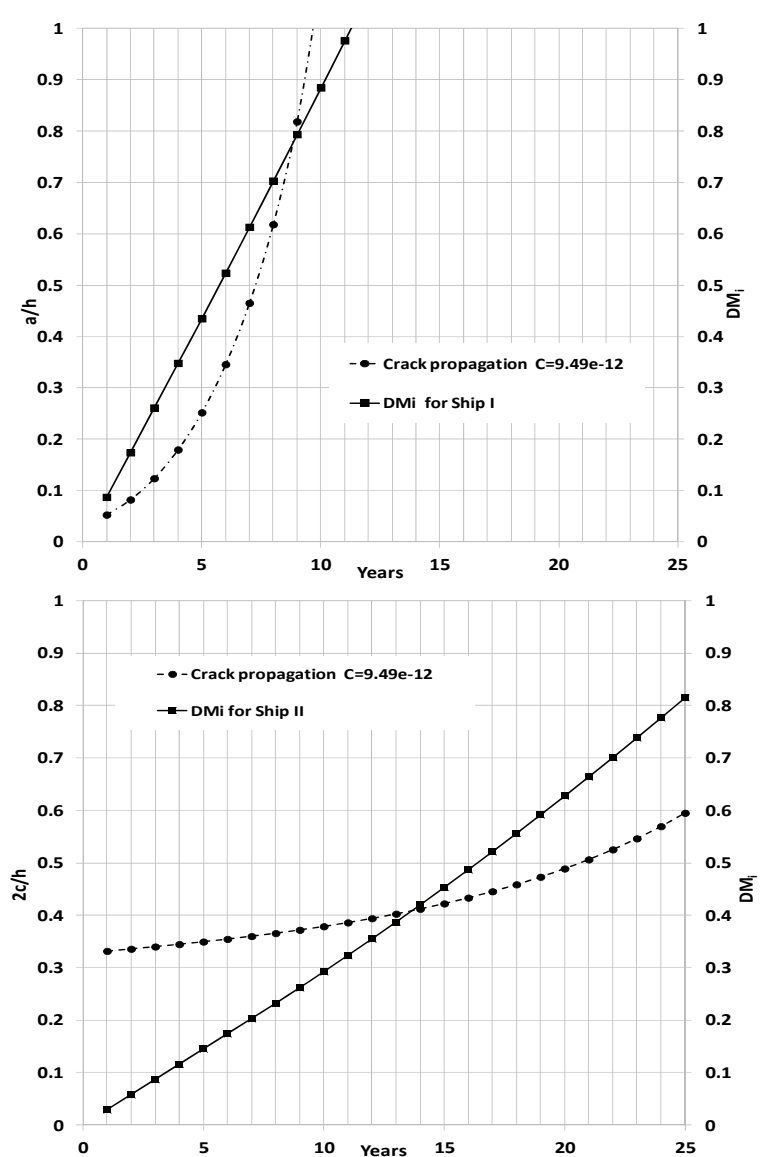

Figure 14: Crack propagation and accumulated damage for Ship I (up) and Ship II (down)

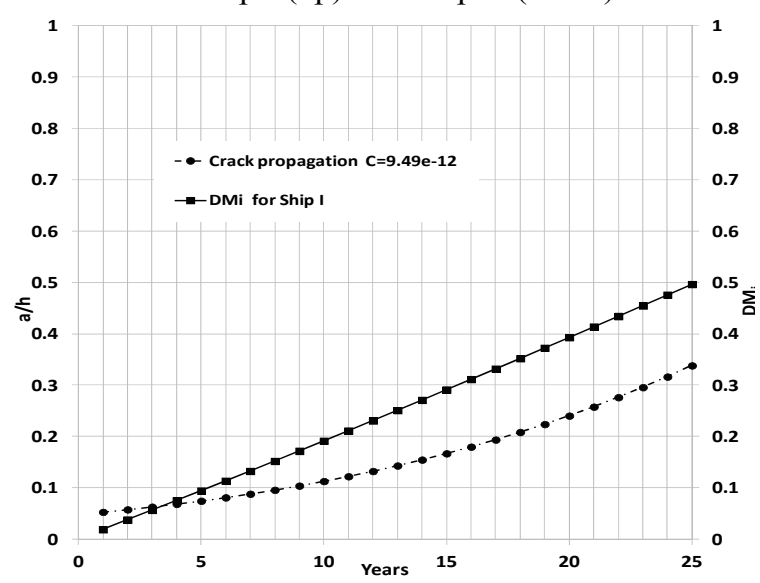

Figure 15 Crack propagation and accumulated damage for Ship I with correction for mean stresses

\section{CONCLUSIONS}

The work presented here describes a practical application of fracture mechanics approach to the fatigue assessment of main deck longitudinals of an oil tanker. The crack propagation at the connection of the deck longitudinal and the web stiffener of the transverse deck girder in two single hull oil tankers is studied. The proposed procedure takes into account the stress increase due to the corrosion degradation of the midship section modulus. The parametric analysis showed in which way and to what 
extent any individual input parameter affects the crack propagation.

The initial crack depth, crack aspect ratio, the crack growth parameter $C$, the stress concentration factor (SCF), the interaction coefficient, $\beta$, the stress ratio $R$ and the crack closure effect strongly affect the rate of the crack propagation. The only parameter that may readily be controlled during the design is the SCF, as a better structural design resulting in a reduction of $\mathrm{SCF}$ and consequently a significant reduction of the crack propagation rate.

Regarding the comparison of the results obtained from S$\mathrm{N}$ and fracture mechanics approaches, it can be concluded that the two approaches agree satisfactory. The ship that did not meet the requirements of fatigue life implied by the S-N approach also had a crack propagation rate outside acceptable limits. The ship that met the requirements of the fatigue assessment implied by the S-N approach also produced satisfactory results with fracture mechanics, as the crack propagation rate was slow.

\section{REFERENCES}

1. Fricke, W. AND Petershagen, H., Detail Design of Welded Ship Structures Based on Hot-Spot Stresses, Proceedings of the Practical Design of Ships and Mobile Units, J. B. Caldwell and G. Ward, Elsevier Science Limited, Vol. 2, pp. 1087-1100, 1992.

2. Fricke, W., Fatigue analysis of welded joints: state of development, Marine Structures, 16, (3), pp. 185-200, 2003.

3. Guedes SoAres, C. And Moan, T., Model Uncertainty in the Long-term Distribution of Wave-induced Bending Moment for Fatigue Design of Ship Structure, Marine Structures, 4, pp. 295-315, 1991.

4. Guedes SoAres, C., Garbatov, Y. AND von SElle, H., Fatigue Damage Assessment of Ship Structural Components Based on the Long-term Distribution of Local Stresses, International Shipbuilding Progress, 50, pp. 35-56, 2003.

5. PARIS, P. AND ERdoGAN, F., A Critical Analysis of Crack Propagation Laws, Journal of Basic Engineering, 85, pp. 528-534, 1963.

6. Guedes Soares, C. AND Garbatov, Y., Reliability of Corrosion Protected and Maintained Ship Hulls Subjected to Corrosion and Fatigue, Journal of Ship Research, 43, pp. 65 - 78, 1999.

7. Petershagen, H., Fricke, W. And Massel, T., Application of the Local Approach to the Fatigue Strength Assessment of Welded Structures in Ships. In: International Institute of Welding, Vol. XIII-1409-91, 1991.
8. RadaJ, D., Sonsino, C. M. And Fricke, W., Recent developments in local concepts of fatigue assessment of welded joints, International Journal of Fatigue, 31, (1), pp. 211, 2009.

9. Dong, P., A Practical Stress Definition and Numerical Implementation for Fatigue Analyses, International Journal of Fatigue, 23, (10), pp. 865-876, 2001.

10. XIAO, Z. G. AND YAMADA, K., A method of determining geometric stress for fatigue strength evaluation of steel welded joints, International Journal of Fatigue, 26, (12), pp. 1277-1293, 2004.

11. Garbatov, Y. AND Guedes Soares, C., Influence of steel strength on the fatigue reliability of welded structural components, International Journal of Fatigue, 26, (7), pp. 753-762, 2004.

12. FenG, G. Q., Garbatov, Y. AND Guedes SOARES, C., Probabilistic model of the growth of correlated cracks in a stiffened panel, Engineering Fracture Mechanics, 84, pp. 83-95, 2012.

13. FenG, G. Q., Garbatov, Y. AND Guedes SOARES, C., Fatigue reliability of a stiffened panel subjected to correlated crack growth, Structural Safety, 36-37, pp. 39-46, 2012.

14. Horn, A. M., Aihara, S., Andersen, M., Biot, M., BOHLMANN, B., REMES, H., VAN DER CAMmen, J., ChOI, B. K., Garbatov, Y., Misha, B., QIAN, X., REMES, H., RIMSBERG, J., SAMANTA, A., WANG, D. AND ZHANG, S., Proceeding of the 18th International Ship and Offshore Structures Congress. Fatigue and Fracture, Committee III, W. Fricke and R. Bronsart, editors, Hamburg: Shifttbautechnische Gesellschaft, pp. 365-434, 2012.

15. Garbatov, Y., RUdAN, S. AND GUEDES SOARES, C., Fatigue damage of structural joints accounting for nonlinear corrosion, Journal of Ship Research, 46, (4), pp. 289-298, 2002.

16. MoAn, T. And Ayala-Uraga, E., Reliabilitybased assessment of deteriorating ship structures operating in multiple sea loading climates, Reliability Engineering \& System Safety, 93, (3), pp. 433-446, 2008.

17. Chakarov, K., Garbatov, Y. AND Guedes SOARES, C., Fatigue analysis of ship deck structure accounting for imperfections, International Journal of Fatigue, 30, (10-11), pp. 1881-1897, 2008.

18. Guedes SoAres, C. AND Garbatov, Y., Reliability of Maintained Ship Hull Subjected to Corrosion and Fatigue, Structural Safety, 20, pp. 201-219, 1998.

19. Kwon, K. And Frangopol, D. M., System Reliability of Ship Hull Structures Under Corrosion and Fatigue, Journal of Ship Research, 56, (4), pp. 234-251, 2012. 
20. IACS, Common Structure Rules for Double Hull Oil Tankers, Consolidated version, July 2010, 2010.

21. JURIŠIĆ, P., PARUNOV, J. AND ŽIHA, K., Uncertainty in corrosion wastage prediction of oil tankers. In: Sustainable Maritime Transportation and Exploitation of Sea Resources, E. Rizzuto and C. Guedes Soares, editors, London: Taylor \& Francis, pp. 395-400, 2012.

22. JANG, B. S., ITO, H., KIM, K. S., SUH, Y. S., JEON, H. T. AND HA, Y. S., A study of fatigue crack propagation at a web stiffener on a longitudinal stiffener, Journal of Marine Science and Technology, 15, (2), pp. 176-189, 2010.

23. Almar-NAEss, A., Fatigue Handbook, Offshore Steel Structures: Tapir, 1985.

24. Lotsberg, I. AND SAlama, M. M., Crack propagation versus crack initiation lives of FPSO weld details, Proceedings of the 29th International Conference on Ocean, Offshore and Arctic Engineering, Shanghai, China, 2010, Paper OMAE2010-20944

25. BS7910, British Standard BS7910, Guide to methods for assessing the acceptability of flaws in metallic structures, London: BSI, 2005.

26. LASSEN, T. AND RECKO, N., Fatigue Life Analysis of Welded Structure: ISTE, 2006.

27. DNV, Fatigue Assessment of Ship Structures, Classification Notes No 30.7, 2010.

28. StePhENS, R. R., FATEMI, A., Fuchs, O. H. AND STEPHENS, R. R., Metal Fatigue in Engineering: John Wiley \& Sons, 2001.

29. WANG, G., LEe, A. K., IVANOV, L., LyNCH, T. J., Serratella, C. AND BASU, R., A statistical investigation of time-variant hull girder strength of aging ships and coating life, Marine Structures, 21, (2-3), pp. 240-256, 2008.

30. DNV, Recommended Practice, Fatigue Design of Offshore Steel Structures, DNV-RP-C203, 2010.

31. PALMGREN, A., Die Lebensdauer von Kugellagern, VDI-Zeitschrift 68, p. 339, 1924.

32. Hughes, O. AND PAIK, J. K., Ship Structural Analysis and Design: The Society of Naval Architects and Marine Engineers, 2010.

33. Frost, N., Marsh, K. AND PooK, L., Metal Fatigue: Claderon Press, 1974.

34. Guedes SoAres, C. AND Dogliani, M., Probabilistic Modelling of Time Varying StillWater Load Effects in Tankers, Marine Structures, 13, (2), pp. 129-143, 2000. 
Trans RINA, Vol 155, Part A1, Intl J Maritime Eng, Jan-Mar 2013 